\title{
HYPERBILIRUBINEMIA IN A CHILD ON ANTI-RETROVIRAL THERAPY
}

\author{
Pawan Daga ${ }^{1}$, Ira Shah². \\ ${ }^{1}$ Final year MBBS, Department of Paediatrics, Seth G S Medical College, Mumbai, \\ ${ }^{2}$ Consultant in Pediatric Infectious Diseases, Levioza Health Care, Mumbai, India.
}

\section{KEYWORDS}

Atazanavir, Jaundice, HIV

\section{ARTICLE HISTORY}

Received 3 September 2019

Accepted 3 September 2019

\section{Clinical Problem:}

A 20 years old HIV infected girl on anti-retroviral therapy (ART) since the age of 12 years presented with jaundice for 3 months. There was no fever. She was initially on stavudine (d4T), lamivudine (3TC) and efavirenz (EFV) till the age of 17 years and was subsequently shifted to abacavir (ABC), lamivudine (3TC) and lopinavir/ ritonavir (LPV/r) in view of virological failure. In view of high pill burden and undetectable viral load, LPV/ $r$ was omitted and Atazanavir/ritonavir (ATZ/r) $(300 / 100 \mathrm{mg})$ was started 3 months ago and $A B C$ and $3 T C$ were continued. Subsequently, the girl developed jaundice. Her total bilirubin 3 months ago was $3.8 \mathrm{mg} / \mathrm{dL}$ with a direct bilirubin of $1.98 \mathrm{mg} / \mathrm{dL}$. Currently, her total bilirubin was $2.8 \mathrm{mg} / \mathrm{dL}$ with a direct bilirubin of 0.78 $\mathrm{mg} / \mathrm{dL}$. Her liver transaminases, serum lactate and lipid levels were normal. Hepatitis B and Hepatitis C Elisa was negative.

What is the cause of the jaundice and how to manage the jaundice?

\section{Discussion:}

Liver function test (LFT) abnormalities are frequently identified in HIV patients. The common causes of jaundice in these patients are drug-induced hyperbilirubinemia, alcoholic liver disease, opportunistic infections and neoplasms. ${ }^{1}$ ATZ is a protease inhibitor. It has favorable pharmacokinetics that enables oncedaily dosing which helps in reducing pill burden. It also has a better lipid profile as compared to other protease inhibitors. ${ }^{2}$ It is also safe to use during pregnancy but neonatal hyperbilirubinemia should be monitored. ${ }^{3}$ The common side effects associated with ATZ are headache, nausea, jaundice, insomnia and fever. Atazanavir competitively inhibits UDP glucuronosyltransferase (UGT1A1) - a microsomal enzyme responsible for bilirubin conjugation in the hepatocytes. This results in unconjugated hyperbilirubinemia which is not associated with hepatic injury. ${ }^{4}$ ATZ induced hyperbilirubinemia is more common in the presence of UGT $1 A 1 * 28$ allele. The frequency of this allele is

\section{CONTACT Pawan Daga}

Email: pawandaga123@gmail.com

Address for Correspondence: Pawan Daga, Seth G S Medical College, Parel, Mumbai, India 400012.

(c)2020 Pediatric Oncall more in Indians, Caucasians and African Americans than the rest of the world. ${ }^{4}$ Bilirubin levels start to rise within a week of initiating ATZ. Commonly the bilirubin levels in the serum are markedly elevated for lengthy periods and the levels fluctuate with time. In one cohort study comprising of $1150 \mathrm{HIV}$ infected patients, the cumulative incidence of grade 3 and 4 hyperbilirubinemia (equal to $>2.5$ and $>5$ times the upper limit of normal, respectively) was markedly higher among ATZ-exposed patients, occurring in $30 \%$ after 1 year of exposure, $73 \%$ after 5 years, and $84 \%$ after 8 years, compared with $1 \%, 4 \%$, and $7 \%$, respectively, among those not exposed to ATZ. ${ }^{5}$ However this side effect does not appear to degrade liver functions, quality of life or adherence; hence did not affect clinical outcomes.5,6 It is important to counsel patient beforehand regarding the safety and long term benefit of this drug to improve adherence. Increasing bilirubin concentration has been seen with higher plasma ATZ concentration, hence patients on the ritonavir-boosted ATZ regimen may benefit with removing ritonavir. ${ }^{7}$ This should be considered only when the HIV viral load is undetectable and there is clinically evident jaundice.

\section{Compliance with ethical standards \\ Funding: None \\ Conflict of Interest: None}

\section{References:}

1. Chalasani N, Wilcox CM. Etiology, evaluation, and outcome of jaundice in patients with acquired immunodeficiency syndrome. Hepatology. 1996; 23: 728-33.

2. Havlir DV, O'marro SD. Atazanavir: new option for treatment of HIV infection. Clin Infect Dis. 2004; 38: 1599-604.

3. Mandelbrot L, Mazy F, Floch-Tudal C, Meier F, Azria E, Crenn-Hebert $C$, et al. Atazanavir in pregnancy: impact on neonatal hyperbilirubinemia. Eur J Obstet Gynecol Reprod Biol. 2011;157:18-21.

4. Beutler E, Gelbart T, Demina A. Racial variability in the UDPglucuronosyltransferase 1 (UGT1A1) promoter: a balanced polymorphism for regulation of bilirubin metabolism? Proc Natl Acad Sci U S A. 1998; 95: 8170-4.

5. Laprise C, Baril JG, Dufresne S, Trottier H. Atazanavir and other determinants of hyperbilirubinemia in a cohort of 
1150 HIV-positive patients: results from 9 years of followup. AIDS Patient Care STDS. 2013;27:378-86

6. McDonald C, Uy J, Hu W, Wirtz V, Juethner S, Butcher D, et al. Clinical Significance of Hyperbilirubinemia Among HIV-1-Infected Patients Treated with Atazanavir/Ritonavir Through 96 Weeks in the CASTLE Study. AIDS Patient Care
STDS. 2012; 26:259-64.

7. Achenbach CJ, Darin KM, Murphy RL, Katlama C. Atazanavir/ritonavir-based combination antiretroviral therapy for treatment of HIV-1 infection in adults. Future Virol. 2011; 6:157-177 